\title{
EL DOCENTE Y \\ LOS PROGRAMAS ESCOLARES. \\ LO INSTITUCIONAL Y LO DIDÁCTICO
}

Díaz Barriga, Ángel

Ediciones Pomares, Barcelona, 2005, 159 p.

\section{EL AUTOR}

Ángel Díaz Barriga es doctor en pedagogía por la Facultad de Filosofía y Letras de la UNAM. Investigador titular definitivo y profesor en la División de Estudios de Posgrado de la Facultad de Filosofía y Letras, de la misma universidad. Fue director del Centro de Estudios sobre la Universidad (1995-2003). Ha trabajado como profesor invitado en universidades mexicanas y latinoamericanas y, desde 1987, es miembro del Sistema Nacional de Investigadores, con el nivel III. Es autor de Didáctica y Currículo; Ensayos sobre la problemática curricular; Tarea docente y Empleadores y egresados universitarios, coautor o coordinador de once libros; autor de más 80 artículos en revistas especializadas en educación y de más de 1130 ponencias en eventos nacionales e internacionales.

\section{CONTENIDO}

El autor explica el acercamiento al estudio sobre El docente y los programas escolares. Asimismo ofrece una visión histórica sobre los programas de estudio en el ámbito de la didáctica: la estructuración del sistema educativo, la influencia de la pedagogía alemana, los modelos centrados en los objetivos y la elaboración de programas. 
Sustenta dos modelos educativos en tensión: uno originado en los debates del siglo XIX y otro en la conformación pedagógica pragmática del siglo XX.

Se propone que el trabajo docente requiere técnicas originalmente formuladas y conceptualmente sustentadas

\section{LA CONFORMACIÓN DE PLANES Y PROGRAMAS DE ESTUDIO EN LA PEDAGOGÍA DEL SIGLO XX}

- A través de los planes y programas, la institución educativa establece una propuesta de formación.

- La organización del sistema educativo, tal como se conoce a nivel internacional, se realiza en el siglo XXI.

- Surgimiento de la concepción pragmática: Evolución social del concepto de eficiencia. Pensamiento tecnocrático. La finalidad central de la educación era educar para el trabajo. Gestación de una pedagogía industrial.

- Al docente se le considera como un operario en línea de producción. Intento por despojar al docente de la dimensión intelectual de su trabajo.

- Las propuestas educativas que emanan de la pedagogía pragmática poseen una visión antiética.

- Noción de "programas de estudio»

- Propia del siglo XX. Aunque en el siglo XVI las escuelas de la Compañía de Jesús establecieron la Ratio atque institutio studiorum societatis Jesu (más un esquema de estudios que una tabla secuencial de contenidos), Comenio en el siglo XVII utilizó el término «plan de estudios» para referirse al conjunto de temas a trabajar.

- La conformación del sistema educativo del siglo XIX impuso otras exigencias a la pedagogía: llevó a desarrollar una concepción cada vez más burocrática de la enseñanza.

- La pedagogía de control y los objetivos conductuales

- Educación centrada en la supervisión y control de maestros y alumnos. 
- Principios básicos de la administración en la elaboración de planes y programas.

- Los psicólogos estructuraron objetivos conductuales para diversos grados escolares y materias.

\section{DOCENTES, PROGRAMAS DE ESTUDIO E INSTITUCIÓN}

- Varias concepciones sobre el sentido institucional de los instrumentos: los planes son para algunas instituciones normas y para otras sólo una orientación.

- La institucionalidad proviene de la aprobación de las autoridades educativas y de las instancias de gobierno.

- La aprobación de éstos se mueve en tres esferas: la burocráticoadministrativa, la académica y la de poder.

\section{- Esfera burocrática}

- El programa es un elemento central para planificar los cursos.

- Cuando se considera la norma a seguir, pretenden garantizar que todos los maestros la cumplan.

- Cuando se juzga que son orientaciones, se busca que el maestro pueda efectuar propuestas e interpretaciones. Pocas instituciones entienden el programa como trabajo colectivo. Se revindica la función intelectual y social del maestro.

\section{- Lo académico y los académicos}

- Crítica sostenida y fundada a la falta de espacios académicos en las instituciones de educación superior.

- Solamente las universidades públicas tienen la facultad de establecer sus propios currículos.

- La carencia o el error educativo no se consideran como fuente de superación.

- La formación de los estudiantes constituye, en realidad, el núcleo central de la tarea docente.

- El plan y programas de estudio pueden convertirse en un eje de conflictos entre los intereses intelectuales y pedagógicos del docente y de la institución. 
- Un problema de legitimación, poder y hegemonía

- Todo proceso de instauración de planes genera problemas de legitimidad en el interior de la institución.

- Toda propuesta lleva implícita una posición teórica, ideológica y técnica.

- Toda propuesta curricular es un acto de poder.

- Se deben establecer, a través del diálogo, fundamentos para una orientación aceptada por los académicos y estudiantes.

\section{FUNCIONES, ESTRUCTURAS}

\section{Y ELABORACIÓN DE LOS PROGRAMAS}

- Programa: Documento oficial de carácter nacional en el que se indican el conjunto de contenidos a desarrollar en determinado nivel.

- Programación: Apoyo educativo, didáctico y específico realizado por los profesores para un grupo de alumnos concreto.

- En el contexto de la pedagogía pragmática emerge la idea de una programación uniforme: existencia de un programa único que debe ser cubierto puntualmente.

- Atender el problema de la multiplicidad resulta indispensable, requiere ser tomado en cuenta en la elaboración de planes y programas de estudio.

- Deben articularse ambos elementos: la planificación curricular global, que organiza una institución escolar, y la necesidad de respetar los procesos, formas de trabajo y condiciones particulares de cada escuela o grupo.

\section{- Estructura}

- Sistema legal o administrativo de la institución escolar.

- Concepción educativa.

- El rol del programa en el contexto del plan de estudios.

- Tipos de programas por sus funciones

- Programas del plan de estudios.

- Programas de las academias o grupos de maestros.

- Programas de cada docente. 
- Programas del plan de estudios

- Posibilita la visión grupal del plan.

- Carácter indicativo.

- Contenidos básicos del curso.

- Programas de los grupos académicos docentes

- Orientar el trabajo del grupo de docentes de una institución.

- Orientar los procesos de acreditación fuera del curso regular.

- La actividad no puede centrarse sólo en la elaboración de objetivos instruccionales.

- Interpretación del planteamiento sintético que efectúa el programa del plan de estudios.

- Determinación de los contenidos básicos

- Los contenidos cumplen una doble función: proporcionar información o posibilitar el desarrollo de un proceso de pensamiento. Promover el desarrollo de estrategias de resolución de problemas y de adquisición de información.

- Establecimiento de formas de acreditación Es necesario tener en cuenta:

- Legislación nacional e institucional que se aplique al respecto.

- Las características del contenido.

- El grado de madurez personal y académica que muestran los estudiantes.

- Una noción de aprendizaje que reconozca la importancia del pensamiento analítico, sintético, reflexivo y la vinculación del conocimiento con los problemas de la realidad.

- Selección y organización de contenidos

- Motivo de presiones, debate entre posiciones epistemológicas, teóricas, políticas y pedagógicas vinculadas con la tarea educativa.

- Las precisiones en torno a la bibliografía guardan una estrecha relación con el nivel donde se lleva a cabo el curso. 
- Los programas del docente

- Elaborado por el docente responsable de impartir una asignatura.

- Concepción de su rol profesional.

- Desarrollar imaginación pedagógica.

- Síntesis de una serie de fundamentaciones.

\section{EL CONTENIDO}

- Orden de enseñanza (fácil a difícil; de lo general a lo particular; de lo concreto a lo abstracto).

- Establecimiento de un orden lógico, actual y significativo.

\section{- Complejidad}

- Problema epistemológico de la estructura.

- Construcción individual que cada ser humano realiza de ese conocimiento.

- Interacción de sujetos, de dinámicas institucionales.

- Necesidad de una formación integral, una educación amplia y no sólo útil.

- Tomar en cuenta los conceptos de memoria a corto plazo y a largo plazo.

- Relación de los contenidos con los intereses de una cultura dominante.

- Problemas en el tratamiento del contenido

- El mundo que rodea al estudiante: informática, electrónica, medios masivos de información, entre otros.

- Los contenidos pueden ser enciclopédicos (recuperación de todo el conocimiento acumulado por la sociedad) o cíclicos (reiteración en los diversos ciclos del sistema educativo de los mismos contenidos con mayor información).

- Acercar al estudiante a elementos que le sean pertinentes.

- Las reformas que actualizan los sistemas educativos de Latinoamérica siguen siendo modernizadores de la pobreza. 
- Los organismos internacionales (Banco Mundial, CEPAL y UNESCO) desarrollan un papel significativo en la construcción de una pedagogía en América Latina.

- Falta de creatividad en el tratamiento del contenido.

- Han surgido propuestas neoenciclopédicas, que tienden a privilegiar la parcelación del conocimiento, en lugar de ofrecer formas novedosas.

\section{MÉTODOS, ACTIVIDADES}

\section{Y SUJETOS DE LA EDUCACIÓN}

\section{- Insuficiencia del saber psicológico}

- Elementos repetitivos en el planteamiento metodológico.

- En la actualidad se considera suficiente el saber psicológico para organizar las actividades de aprendizaje.

- Urgencia de la renovación metodológica

- Surge a partir de las propuestas emanadas de la propia política educativa.

- Uno de los principales promotores de la innovación educativa es el discurso político.

- La descentralización educativa, la evaluación de la calidad, la eficiencia de la educación, el establecimiento de cuotas en las universidades son expresiones del Banco Mundial.

- Cuentan con tres elementos: orientaciones ideológicas, bagaje conceptual, su propia experiencia.

- Cambios para insertar innovaciones

- En el seno de la sociedad: Cambios en la política de los medios de comunicación (valores individualistas, modo fácil y cómodo de vivir, modismos lingüísticos...). Conformación de una conciencia colectiva.

- En el ámbito escolar: En la dinámica académica y sus órganos institucionales. Promover espacios intelectuales para el debate, congresos académicos. Readecuar las instalaciones. Conformar una biblioteca. Construcción y conservación de material didáctico de bajo costo. 
- Ansiedad creadora

- El docente debe desarrollar diversas estrategias para resolver las situaciones inmediatas que debe enfrentar.

- Mientras el docente no perciba que desempeña un papel central en la construcción metodológica, no tendrá construcciones para enfrentar con creatividad su tarea educativa.

\section{- Función intelectual del docente}

- Vincular la imagen del docente a la de investigador.

- La función docente es necesariamente intelectual y, por lo tanto, padece todos los problemas que el intelectual experimenta en la sociedad contemporánea.

\section{- Relación método-contenido}

- Necesidad de modificar la concepción enciclopédica que se tiene del conocimiento.

- Las disciplinas cuya metodología de conocimiento es deductiva, hermenéutica o inductiva necesitan ser transmitidas respetando estos supuestos lógicos.

\section{- Propuestas metodológicas y psicológicas}

- El desarrollo de la didáctica se enriqueció de manera sorprendente por la evolución del conocimiento psicológico.

- Fundamento de las propuestas educativas: La psicología evolutiva, después la de aprendizaje y personalidad.

- Apoyo de la psicología: Debate sobre el aprendizaje y estructuración del ser humano.

- Matices de las concepciones psicológicas: Aprendizaje como bagaje genético, como resultado de la interacción de elementos congénitos y el medio en el que el sujeto se desarrolla, como algo fundamentalmente individual...

- Varias perspectivas psicológicas ofrecen cursos de formación docente. Destacan las de corte cognoscitivo (Piaget, Bruner, Vygostky). 
- Piaget: Desarrollo cognitivo a partir de una construcción individual. Primero un pensamiento concreto y operatorio, y luego simbolización y abstracción.

- Hilda Taba: introducción, desarrollo, generalización y aplicación.

- Bruner: Análisis del momento actual, el papel de la sociedad y la cultura. Intervención del adulto en el proceso de aprendizaje.

- Aprendizaje y teoría de la experiencia

- Dewey: La experiencia puede generar la curiosidad y fortalecer la iniciativa.

- Posibilita la adquisición del proceso formal del pensamiento.

- Las teorías sobre los grupos

- El empleo de propuestas grupales se ha reducido a una dimensión técnica.

- Diálogo como eje de la práctica pedagógica.

\section{EL EXAMEN}

\section{- Ambigüedad conceptual}

- Problemática de la evaluación.

- El concepto de evaluación se utiliza inicialmente para referirse a cuestiones del aprendizaje.

- Se trasciende de la evaluación del rendimiento escolar hacia la evaluación educativa (docente, método, programa, institución, plan de estudios, sistema educativo).

- Historia del examen

Génesis social:

- Burocracia china (1200 a.C.): Selección del personal. El examen nace como una exigencia social.

- Universidad medieval: Mostrar en público el grado de madurez intelectual que adquirió el estudiante. 
- Reforma-Contrarreforma: Papel metodológico y supervisión permanente.

- Siglo XX: La teoría del test para medir el aprendizaje.

- Cuatro enunciados básicos

- Es falso el principio de que, a mejor sistema de exámenes, mejor sistema de enseñanza.

- Se puede afirmar que toda noción de examen lleva, de forma implícita, una de aprendizaje.

- El examen no puede ser justo ni puede ser objetivo.

- A través del examen se pervierte la relación pedagógica.

- Inversión de las relaciones pedagógicas El examen opera una serie de inversiones pedagógicas:

- Convierte las relaciones de saber en relaciones de poder.

- Convierte los problemas sociales en problemas técnicos.

- Reduce los problemas metodológicos a problemas de rendimiento.

\section{- Evaluación y acreditación}

- La evaluación se concibe como interpretación de medidas, o bien como control.

- El objeto básico es proporcionar elementos para la comprensión de lo que sucede en el aula.

- Relación con la asignatura.

- La acreditación responde a una lógica institucional, no del aprendizaje.

- Responde al sistema de institucionalización del sistema escolar.

- Se efectúa a partir del programa de estudios.

\section{VALORACIÓN CRÍTICA}

El doctor Díaz Barriga ofrece elementos didácticos para la construcción de una reflexión de la tarea docente, concibe a éste como la persona que requiere atender a los programas educativos, así como la relación con los procesos de enseñanza y de aprendizaje, y sus 
imbricaciones. El aspecto preponderante en este libro es concebir a un docente que debe vivir desde la pasión por enseñar y el afán por aprender.

La docencia tiene como objeto de estudio el logro de aprendizajes significativos y esta obra presenta los puntos álgidos de los aciertos, los errores, las necesidades y las demandas que hoy presenta la enseñanza a partir de Comenio y de Freinet, autores a los cuales actualiza y renueva.

El autor insiste en que la tarea educativa del docente es la formación de los estudiantes, aspecto relevante y trascendente a tomar en consideración en la tarea educativa.

Un aspecto de vital repercusión es la exposición y sustentación del autor para lograr la vinculación de la imagen del docente a la de investigador.

El exponer con claridad la didáctica, en sus implicaciones educativas, de los planes y los programas de estudio, del tratamiento de los contenidos educativos, de las estrategias didácticas y del examen como medio de la evaluación educativa, es plantear a los docentes el compromiso personal, profesional y social que poseen en el ámbito educativo. 
